Board of Governors of the Federal Reserve System

\author{
International Finance Discussion Papers \\ Number 984 \\ November 2009 \\ Portfolio Inertia and the Equity Premium \\ Christopher Gust \\ David López-Salido
}

NOTE: International Finance Discussion Papers are preliminary materials circulated to stimulate discussion and critical comment. References to International Finance Discussion Papers (other than an acknowledgement that the writer has had access to unpublished material) should be cleared with the author or authors. Recent IFDPs are available on the Web at www.federalreserve.gov/pubs/ifdp/. This paper can be downloaded without charge from Social Science Research Network electronic library at www.ssrn.com. 


\title{
Portfolio Inertia and the Equity Premium*
}

\author{
Christopher Gust and David López-Salido ${ }^{\dagger}$ \\ Federal Reserve Board
}

September 2009

\begin{abstract}
We develop a DSGE model in which aggregate shocks induce endogenous movements in risk. The key feature of our model is that households rebalance their financial portfolio allocations infrequently, as they face a fixed cost of transferring cash across accounts. We show that the model can account for the mean returns on equity and the risk-free rate, and generates countercyclical movements in the equity premium that help explain the response of stock prices to monetary shocks. The model is consistent with empirical evidence documenting that unanticipated changes in monetary policy have important effects on equity prices through changes in risk.
\end{abstract}

Keywords: limited financial market participation, infrequent portfolio adjustment, equity premium

JEL classification: E32, E44

${ }^{*}$ We thank Orazio Attanasio, Gianluca Benigno, Martin Bodenstein, V.V. Chari, John Driscoll, Mike Dotsey, Luca Guerrieri, Pat Kehoe, Narayana Kocherlakota, Sylvain Leduc, Andy Levin, Ricardo Nunes, Victor Rios-Rull, Harald Uhlig, Annette Vissing-Jørgensen, Mike Woodford, and seminar participants at the Bank of Spain, Federal Reserve Board, Georgetown University, International Monetary Fund, and the Federal Reserve Banks of Minneapolis and San Francisco for useful comments. The views expressed in this paper are solely the responsibility of the authors and should not be interpreted as reflecting the views of the Board of Governors of the Federal Reserve System or of any other person associated with the Federal Reserve System.

${ }^{\dagger}$ Corresponding Author: Christopher Gust. Email: christopher.gust@frb.gov, david.lopez-salido@frb.gov. 


\section{Introduction}

Monetary policy primarily affects the macroeconomy through its effect on financial markets. In standard monetary models, this interaction between the financial and real sides of the economy occurs through short-term interest rates, as changes in monetary policy affect the conditional mean of the short-term interest rate which in turn influences macroeconomic variables such as output, employment, and inflation. These models, however, abstract from another channel through which monetary policy affects financial markets and the macroeconomy. In these models, there is little or no role for monetary policy to influence the conditional variances of variables or the perceived riskiness of the economy. ${ }^{1}$ In contrast, Bernanke and Kuttner (2005) provide evidence that monetary policy does affect risk, suggesting that standard monetary models are potentially missing an important channel through which monetary shocks propagate from the financial to the real economy. They show that, while an unanticipated easing of monetary policy lowers real short-term interest rates, it also has a significant effect on equity returns occurring through a reduction in the equity premium.

In this paper, we develop a DSGE model in which monetary policy affects the economy through the standard interest rate channel and through its effect on economic risk. The key feature of the model is that asset and goods markets are segmented, because it is costly for households to transfer funds between these markets. Accordingly, they may only infrequently update their desired allocation of cash between a checking account devoted to purchasing goods and a brokerage account used for financial transactions. The optimal decision by an individual household to rebalance their cash holdings is a state-dependent one, reflecting that doing so involves paying a fixed cost in the presence of uncertainty. Households are heterogenous in this fixed cost, and only those households that rebalance their portfolios during the current period matter for determining asset prices. Because the fraction of these household changes over time

\footnotetext{
${ }^{1}$ See Alvarez, Atkeson, and Kehoe (2007) for an extended discussion of this point. In a companion paper, Alvarez, Atkeson, and Kehoe (2009) argue that the evidence on the relationship between interest rates and exchange rates is consistent with movements in these variables that are driven mainly by changes in conditional variances.
} 
in response to both real and monetary shocks, risk in the economy is both time-varying and endogenous.

We show that the model, unlike standard monetary models, generates countercyclical movements in the equity premium and in particular, a reduction in the equity premium resulting from an easing of monetary policy. For reasonable calibrations of the model, the reduction in the equity premium is an important determinant of the response of stock prices to a monetary policy shock.

We also examine the model's ability to account for the mean returns on equity and the risk-free rate. As shown by Mehra and Prescott (1985), standard representative agent models with power utility have difficulty quantitatively accounting for these moments. For reasonable calibrations of monetary and technology shocks, our model is able to match the observed means on equity and risk-free rates with a power utility function that implies constant relative risk aversion equal to two. We show that to match these moments, the average fraction of households that reallocates funds across markets can not be too large. For a constant relative risk aversion of two, the average fraction of rebalancers in a quarter must range between roughly 10 to 20 percent. Underlying this average fraction of rebalancing, there is a considerable degree of heterogeneity, with some households rebalancing every period and another fraction rarely rebalancing away from their initial allocation.

Recent microdata on household finance provides strong support for infrequent portfolio rebalancing. For instance, in two recent papers, Calvet, Campbell, and Sodini (2009a) and Calvet, Campbell, and Sodini (2009b) document that, while there is little rebalancing of the financial portfolios of stockholders by the average household, there is a great deal of heterogeneity at the micro level with some households rebalancing these portfolios very frequently. In addition, using information on asset holdings from the PSID, Bilias, Georgarakos, and Haliassos (2008) and Brunnermeier and Nagel (2008) provide evidence that household portfolio allocation display substantial inertia. Surveys conducted by the Investment Company Institute (ICI) and the Securities Industry Association (SIA) also suggest that households rebalance their portfolios infrequently. For instance, in 2004, the median number of total equity transactions for an 
individual was four. In addition, sixty percent of equity investors did not conduct any equity transactions during 2004. Finally, in a 2005 survey, the ICI reports that more than two-thirds of the time the proceeds from the sales of stocks by households are fully reinvested. ${ }^{2}$

Our model is most closely related to and builds on the analysis of Alvarez, Atkeson, and Kehoe (2009). They introduce endogenously segmented markets into an otherwise standard cash-in-advance economy and show how changes in monetary policy can induce fluctuations in risk. However, our model differs from theirs in two important respects. First, we incorporate production and equity returns. Second and more importantly, in their model, risk is endogenous, because the fraction of households that participates in financial markets is state-dependent. In our model, it is costly to reallocate cash between the asset and goods markets from a household's initial allocation. In other words, endogenous asset segmentation occurs along an intensive margin in our model rather than an extensive margin. This distinction is important, because we show that for reasonable calibrations the endogenous participation model can not match the average equity premium and monetary policy shocks have no effect on the equity premium. ${ }^{3}$

Our paper is also related to portfolio choice models that emphasize infrequent adjustment. In this literature, the paper most closely related to ours is Abel, Eberly, and Panageas (2007). ${ }^{4}$ They also model infrequent adjustment of cash between a transaction account used to purchase goods and another account used to purchase financial assets. Their framework differs from ours, since they do not consider the role of monetary policy and use a partial equilibrium framework in which returns are exogenous. However, they show that infrequent portfolio adjustment can arise due to rational inattention on the part of households. ${ }^{5}$

\footnotetext{
${ }^{2}$ See, Figure F.7, "Disposition of Proceeds from most recent sale of individual stocks", in ICI 2005.

${ }^{3}$ Polkovnichenko (2004), Vissing-Jorgensen (2002), Vissing-Jorgensen (2003), and Gomes and Michaelides (2006) also show that it is difficult to match the equity premium in a model with endogenous stock market participation. Guvenen (2005) considers a model in which stock market participation is fixed exogenously and shows that this feature in addition to heterogeneity in preferences can help account for the average equity premium.

${ }^{4}$ Also, see Lynch (1996), Marshall and Parekh (1999), Gabaix and Laibson (2001), and more recently, Bacchetta and van Wincoop (2009) and Bonaparte and Cooper (2009).

${ }^{5}$ See also Reis (2006), who uses a rational inattentive framework to explain the excess sensitivity of consump-
} 
The rest of this paper proceeds as follows. The next section describes the model and its calibration. Section 3 presents the results, emphasizing the model's ability to match unconditional moments such as the mean returns on equity and a risk-free asset as well as the conditional responses of these variables to a monetary policy shock. Section 4 concludes and discusses directions for future research.

\section{The Model}

The model builds on the cash-in-advance economy of Alvarez, Atkeson, and Kehoe (2009), which we extend to incorporate equity prices. Our approach differs from theirs, since we emphasize that time-varying risk is driven by costly portfolio rebalancing of financial accounts rather than limited participation in financial markets.

The economy is populated by a large number of households, firms, and a government sector. Trade occurs in financial and goods markets in separate locations so that they are segmented from each other. After choosing an initial non-state contingent plan that allocates funds across asset and goods markets, households must pay a fixed cost to make state contingent transfers between these markets. This fixed cost is constant over time but varies across households. We refer to a household's cash balances in the goods market as her checking account, and her cash balances in the asset market as her brokerage account. An active household is one that pays her fixed cost and rebalances cash across these two accounts, and an inactive household does not.

There are two sources of uncertainty in our economy - aggregate shocks to technology, $\theta_{t}$, and money growth, $\mu_{t}$. We let $s_{t}=\left(\theta_{t}, \mu_{t}\right)$ index the aggregate event in period $t$, and $s^{t}=\left(s_{1}, \ldots, s_{t}\right)$ denote the state, which consists of the aggregate shocks that have occurred through period $t$.

tion to past information and its excess smoothness to permanent income shocks. 


\section{$2.1 \quad$ Firms}

There is large number of perfectly competitive firms, which each have access to the following technology for converting capital, $K\left(s^{t-1}\right)$, and labor, $L\left(s^{t}\right)$, into output, $Y\left(s^{t}\right)$ at dates $t \geq 1$ :

$$
Y\left(s^{t}\right)=\exp \left(\theta_{t}\right) K\left(s^{t-1}\right)^{\alpha} L\left(s^{t}\right)^{1-\alpha} .
$$

The variable $\theta_{t}$ is an aggregate technology shock which follows a first-order autoregressive process:

$$
\theta_{t}=\rho_{\theta} \theta_{t-1}+\epsilon_{\theta t}
$$

where $\epsilon_{\theta t} \sim N\left(0, \sigma_{\theta}^{2}\right)$ for all $t \geq 1$.

Capital does not depreciate, and there exists no technology for increasing or decreasing its magnitude. We adopt the normalization that the aggregate stock of capital is equal to one. Labor is supplied inelastically by households, and its supply is normalized to one.

Firm production begins at date 1. Following Boldrin, Christiano, and Fisher (1997), we assume that firms have a one-period planning horizon. To operate capital in period $t+1$, a firm must purchase it at the end of period $t$ from those firms operating during period $t$. To do so, a firm issues equity $S\left(s^{t}\right)$ at dates $t \geq 0$, and purchases capital subject to its financing constraint,

$$
P_{k}\left(s^{t}\right) K\left(s^{t}\right) \leq S\left(s^{t}\right)
$$

where $P_{k}\left(s^{t}\right)$ denotes the price of capital.

A firm derives revenue from its sale of output, $P\left(s^{t+1}\right) Y\left(s^{t+1}\right)$, and the sale of its capital stock, $P_{k}\left(s^{t+1}\right) K\left(s^{t}\right)$, at the end of period $t+1$. A firm's expenses include its obligations on equity, $\left(1+R^{e}\left(s^{t+1}\right)\right) S\left(s^{t}\right)$, and payments to to labor, $W\left(s^{t+1}\right) L\left(s^{t+1}\right)$. A firm's net revenues, $V\left(s^{t+1}\right)$, including its expenses, must be greater than zero in each state so that:

$$
V\left(s^{t+1}\right)=P\left(s^{t+1}\right) Y\left(s^{t+1}\right)+P_{k}\left(s^{t+1}\right) K\left(s^{t}\right)-\left(1+R^{e}\left(s^{t+1}\right)\right) S\left(s^{t}\right)-W\left(s^{t+1}\right) L\left(s^{t+1}\right) \geq 0 .
$$

The firm's problem at date $t+1$ is to maximize $V\left(s^{t+1}\right)$ across states of nature by choice of $K\left(s^{t}\right)$ and $L\left(s^{t+1}\right)$ subject to (1) and (3). This problem implies that the financing constraint (3) is satisfied as a strict equality in equilibrium. The equilibrium real wage, $w\left(s^{t+1}\right)$ is given by:

$$
w\left(s^{t+1}\right)=\frac{W\left(s^{t+1}\right)}{P\left(s^{t+1}\right)}=(1-\alpha) \frac{Y\left(s^{t+1}\right)}{L\left(s^{t+1}\right)},
$$


Linear homogeneity of the firm's objective, together with the weak inequality in equation (4) imply that $V\left(s^{t+1}\right)=0$ for all $s^{t+1}$ so that:

$$
1+r^{e}\left(s^{t+1}\right)=\frac{1+R^{e}\left(s^{t+1}\right)}{\pi\left(s^{t+1}\right)}=\frac{\left[\alpha \frac{Y\left(s^{t+1}\right)}{K\left(s^{t}\right)}+p_{k}\left(s^{t+1}\right)\right]}{p_{k}\left(s^{t}\right)} .
$$

In the above, $p_{k}\left(s^{t}\right)=\frac{P_{k}\left(s^{t}\right)}{P\left(s^{t}\right)}$ denotes the real price of capital and $\pi\left(s^{t+1}\right)=\frac{P\left(s^{t+1}\right)}{P\left(s^{t}\right)}$ is the economy's inflation rate.

\subsection{Households}

There are a large number of households of type $\gamma$, which denotes a household's fixed cost of making state contingent transfers from a brokerage account to a checking account. This cost is constant across time but differs across household types according to the probability density function $f(\gamma)$.

Brokerage Account. At date 0, a household learns her type and engages in an initial round of trade in the asset market, as goods markets do not open until date 1. With initial asset holdings, $\bar{B}(\gamma)$ in her brokerage account at date 0 , the household purchases equity, $S\left(s_{0}, \gamma\right)$, issued by the firms and a complete set of one-period contingent claims, $B\left(s^{1}, \gamma\right)$, issued by the government. Accordingly, the flow of funds in a household's brokerage account at date 0 is given by:

$$
\bar{B}(\gamma)=S\left(s_{0}, \gamma\right)+\int_{s_{1}} q\left(s^{1}\right) B\left(s^{1}\right) d s_{1},
$$

where $q\left(s^{1}\right)$ is the price of the bond in state, $s^{1}$.

For dates $t \geq 1$, a household's brokerage account evolves according to:

$$
\begin{gathered}
B\left(s^{t}, \gamma\right)+\left(1+R^{e}\left(s^{t}\right)\right) S\left(s^{t-1}, \gamma\right)=\int_{s_{t+1}} q\left(s^{t}, s_{t+1}\right) B\left(s^{t}, s_{t+1}, \gamma\right) d s_{t+1}+ \\
S\left(s^{t}, \gamma\right)+P\left(s^{t}\right) A(\gamma)+P\left(s^{t}\right)\left[x\left(s^{t}, \gamma\right)+\gamma\right] z\left(s^{t}, \gamma\right)
\end{gathered}
$$

where $A(\gamma)$ is a non-state contingent transfer of funds from a household's brokerage account to checking account at date $t$ chosen at date 0 after a household learns her type. A household can 
alter this initial transfer plan by choosing $x\left(s^{t}, \gamma\right) \neq 0$, which requires paying the fixed cost $\gamma$. Accordingly, $z\left(s^{t}, \gamma\right)$ is an indicator variable equal to one if a household opts to pay her fixed cost and make a state-contingent transfer and equal to zero if a household does not.

We view the fixed cost, $\gamma$, as reflecting cognitive costs associated with collecting and processing information necesssary to recompute the optimal portfolio allocation in response to shocks. Our approach is similar to Gabaix and Laibson (2001) and Bacchetta and van Wincoop (2009); however, we emphasize that the decision to reoptimize portfolio holdings is state dependent rather than time dependent. Our approach also shares similarities with Reis (2006), who derives inattentive behavior on the part of households who infrequently adjust their consumption and saving plans using a rational inattentive framework.

The key assumption we make about a household's initial allocation scheme, $A(\gamma)$, is that it is non-state contingent. In principle, a household could choose a time-varying, non-state contingent plan at date 0 and would do so if the model allowed for finite-lived agents with life-cycle considerations. ${ }^{6}$ For example, a household born with low initial assets would save some of her wage income by setting up a plan that at first transferred a fixed amount of funds from her checking account to her brokerage account. However, the household would also set up her transfer scheme to reverse this flow at her expected retirement date, when cash transfers from her brokerage to her checking account become her primary source of cash for consumption. While including financial planning over a household's life cycle would be more realistic, we abstract from such considerations to keep the analysis tractable and simply focus on the nonstate contingent nature of $A(\gamma)$. By incorporating this initial portfolio decision and a fixed cost of altering it in response to shocks, our model is broadly consistent with the micro evidence that many households adjust their portfolio decisions very infrequently. ${ }^{7}$

\footnotetext{
${ }^{6}$ The non-state contingent plan would also need to be time-varying if we incorporated deterministic growth in technology. It is relatively straightforward to do so, and incorporating growth in this way would not alter our conclusions.

${ }^{7}$ See, for example, Souleles (2003) and Ameriks and Zeldes (2004).
} 
Checking Account. For $t \geq 1$, a household purchases goods for consumption, $c\left(s^{t}, \gamma\right)$, and works in the labor market. To purchase goods in period $t$, a household uses cash in her checking account:

$$
P\left(s^{t}\right) c\left(s^{t}, \gamma\right)=M\left(s^{t-1}, \gamma\right)+P\left(s^{t}\right) x\left(s^{t}, \gamma\right) z\left(s^{t}, \gamma\right)+P\left(s^{t}\right) A(\gamma)
$$

At the beginning of period $t$, a household has $M\left(s^{t-1}, \gamma\right)$ dollars in her checking account with which to purchase goods. A household also receives cash from her non-state contingent transfer plan and $P\left(s^{t}\right) x\left(s^{t}, \gamma\right)$ dollars from her brokerage account, if she chooses to incur the fixed cost and transfer additional funds. ${ }^{8}$

Each household inelastically supplies her labor to the economy's firms. With a household's labor supply normalized to one, a household earns real wage income, $w\left(s^{t}\right)$. This wage income is received at the end of the period so it can not be used for current consumption. Accordingly, a household cash in its checking account at the end of period $t$ is given by:

$$
M\left(s^{t}, \gamma\right)=P\left(s^{t}\right) w\left(s^{t}\right)
$$

We have abstracted from the possibility that a household may want to save extra cash in their checking and/or brokerage accounts since equations (8) and (9) always bind. Since incorporating occasionally binding constraints greatly complicates the analysis, we address it in the appendix and in Gust and López-Salido (2009). As discussed there, the main results of our analysis are robust to this possibility.

A household's problem is to choose $A(\gamma)$ and $\left\{c\left(s^{t}, \gamma\right), x\left(s^{t}, \gamma\right), z\left(s^{t}, \gamma\right)\right.$, $\left.M\left(s^{t}, \gamma\right), B\left(s^{t}, \gamma\right), S\left(s^{t-1}, \gamma\right)\right\}_{t=1}^{\infty}$ to maximize:

$$
\sum_{t=1}^{\infty} \int_{s^{t}} \beta^{t} U\left(c\left(s^{t}, \gamma\right)\right) g\left(s^{t}\right) d s^{t}
$$

subject to equations (7)-(10), taking prices and initial holdings of money, bonds, and stocks as given. In equation (11), the function $g\left(s^{t}\right)$ denotes the probability distribution over history $s^{t}$.

\footnotetext{
${ }^{8} \mathrm{~A}$ household can reoptimize by setting $x\left(s^{t}, \gamma\right)<0$, thereby transferring additional cash from her checking to brokerage account. Similarly, a household is free to choose $A(\gamma)<0$.
} 
Endogenous Participation. If households are not able to set up the initial, non-state contingent transfer plan, the model is similar to the endogenous participation framework of Alvarez, Atkeson, and Kehoe (2009). In this case, asset markets are completely segmented from goods markets for agents who do not transfer $x\left(s^{t}, \gamma\right)$ between them. We call this version of the model, the "endogenous participation model", because the decision to transfer funds from asset to the goods market determines whether a household participates in financial markets. In contrast, in the "endogenous rebalancing" model, the decision to transfer funds $x\left(s^{t}, \gamma\right)$ at date $t$ amounts to a rebalancing of cash from a household's initial allocation chosen at date 0 .

\subsection{The Government}

The government issues the economy's one-period state-contingent bonds and controls the economy's money stock, $M_{t}$. Its budget constraints at date 0 is $\bar{B}=\int_{s_{1}} q\left(s_{1}\right) B\left(s^{1}\right) d s_{1}$ where $\bar{B}$ is given, and at dates $t \geq 1$, its budget constraint is:

$$
B\left(s^{t}\right)+M_{t-1}=M_{t}+\int_{s_{t+1}} q\left(s^{t}, s_{t+1}\right) B\left(s^{t}, s_{t+1}\right) d s_{t+1},
$$

with $M_{0}>0$ given. The government injects cash into the economy via a first-order autoregressive process for money growth, $\mu_{t}=\frac{M_{t}}{M_{t-1}}$ :

$$
\mu_{t}=\left(1-\rho_{\mu}\right) \bar{\mu}+\rho_{\mu} \mu_{t-1}+\epsilon_{\mu t}
$$

where $\bar{\mu}>0$, and $\epsilon_{\mu t} \sim N\left(0, \sigma_{\mu}^{2}\right)$ for all $t \geq 1$.

\subsection{Market Clearing}

The economy's resource constraint is:

$$
Y\left(s^{t}\right)=\int_{0}^{\infty}\left[c\left(s^{t}, \gamma\right)+\gamma z\left(s^{t}, \gamma\right)\right] f(\gamma) d \gamma
$$

while market clearing in factor markets requires $K\left(s^{t}\right)=1$ and $L\left(s^{t}\right)=1$. In asset markets, for stock and bond markets to clear at dates $t \geq 0$ we have:

$$
S\left(s^{t}\right)=\int_{0}^{\infty} S\left(s^{t}, \gamma\right) f(\gamma) d \gamma \quad B\left(s^{t+1}\right)=\int_{0}^{\infty} B\left(s^{t+1}, \gamma\right) f(\gamma) d \gamma
$$


At date 0 , we also have $\bar{B}=\int_{0}^{\infty} \bar{B}(\gamma) f(\gamma) d \gamma$. For $t \geq 1$, beginning of the period cash holdings satisfy:

$$
\int_{0}^{\infty}\left\{M\left(s^{t-1}, \gamma\right)+P\left(s^{t}\right)\left[x\left(s^{t}, \gamma\right)+\gamma\right] z\left(s^{t}, \gamma\right)+P\left(s^{t}\right) A(\gamma)\right\} f(\gamma) d \gamma=M_{t}
$$

where the presence of the fixed cost reflects it is paid using cash from the brokerage account.

An equilibrium is a collection of asset prices, $\left\{P_{A}, q\left(s^{t}\right), R^{e}\left(s^{t}\right), P_{k}\left(s^{t}\right)\right\}$, wages, and goods prices, which together with money, bonds, stocks, and allocations, $\left\{c\left(s^{t}, \gamma\right), x\left(s^{t}, \gamma\right), N\left(s^{t-1}, \gamma\right)\right.$, $\left.z\left(s^{t}, \gamma\right)\right\}$ satisfying the household's optimization problem. These prices together with the allocations $\left\{S\left(s^{t-1}\right), K\left(s^{t-1}\right), Y\left(s^{t}\right), L\left(s^{t}\right)\right\}$ satisfies the firm's optimization problem. Finally, the government budget constraint holds and the resource constraint along with the market clearing conditions for capital, labor, bonds, stocks, and money are all satisfied.

\subsection{Equilibrium Characterization}

We now characterize equilibrium consumption and transfers of households. We then discuss the link between the consumption of households that actively rebalance their portfolios (i.e., choose $\left.z\left(s^{t}, \gamma\right)=1\right)$ and equity returns.

\subsubsection{Consumption and Transfers}

We begin by characterizing a household's consumption conditional on her choice of paying the fixed cost of making a state dependent transfer (i.e., her choice of $\left.z\left(s^{t}, \gamma\right)\right)$. To do so, we use the fact that market clearing of factor markets implies that $Y\left(s^{t}\right)=\exp \left(\theta_{t}\right)$. In addition, we can determine the economy's price level and inflation rate by substituting equations (9) and (14) into the money market clearing condition to write:

$$
P\left(s^{t}\right)=M_{t} \exp \left(-\theta_{t}\right), \quad \pi\left(s^{t}\right)=\mu_{t} \exp \left(\theta_{t-1}-\theta_{t}\right)
$$

With these expressions, we can show that the consumption of an inactive household (i.e., one that sets $\left.z\left(s^{t}, \gamma\right)=0\right)$ is given by:

$$
c_{I}\left(s^{t}, \gamma\right)=\frac{w\left(s^{t-1}\right)}{\pi\left(s^{t}\right)}+A(\gamma)=\frac{(1-\alpha) \exp \left(\theta_{t}\right)}{\mu_{t}}+A(\gamma)
$$


From this expression, we can see that inflation is distortionary, since, all else equal, it reduces the consumption of inactive households. Accordingly, an unanticipated increase in money that raises inflation will induce the marginal household to pay her fixed cost and become active. Although the consumption of inactive households rises due to an increase in wages following an unexpected technological improvement, the benefits of being active are even greater, reflecting that active consumption is also boosted by higher capital income. Thus, a technology shock will also boost the number of active households.

There is perfect risk-sharing amongst active households, and following Alvarez, Atkeson, and Kehoe (2002), we assume that the initial asset holdings, $\bar{B}(\gamma)$, of the households implies:

$$
c_{A}\left(s^{t}, \gamma\right)=c_{A}\left(s^{t}\right)
$$

Accordingly, the consumption of active households is independent of $\gamma$. To further characterize, the consumption of active and inactive households, we need to determine $A(\gamma)$. A household's choice of $A(\gamma)$ satisfies:

$$
\sum_{t=1}^{\infty} \int_{s^{t}} \beta^{t}\left[U^{\prime}\left(c_{A}\left(s^{t}\right)\right)-U^{\prime}\left(c_{I}\left(s^{t}, \gamma\right)\right)\right]\left(1-z\left(s^{t}, \gamma\right)\right) g\left(s^{t}\right) d s^{t}=0 .
$$

This latter condition states that in states of the world in which a household is inactive (i.e., $\left.z\left(s^{t}, \gamma\right)=0\right)$, the household chooses $A(\gamma)$ to equate her expected discounted value of marginal utility of its consumption to the expected discounted value of the marginal utility of consumption of the active households. Accordingly, the non-state contingent transfer plan provides some consumption insurance to households with relatively large fixed costs of rebalancing their portfolio allocation. Such households will choose $A(\gamma)>0$ to compensate for their infrequent access to capital income derived from equity markets.

While equation (19) places restrictions on the choice of $A(\gamma)$ for most households, this condition is irrelevant for a household that is active in each state of the world. In this case, a household's choice of $A(\gamma)$ is redundant, since she can use $x\left(s^{t}, \gamma\right)$ to achieve her desired level of consumption.

We now characterize a household's decision for $z\left(s^{t}, \gamma\right)$ given optimal decisions for $c\left(s^{t}, \gamma\right)$, 
$x\left(s^{t}, \gamma\right)$, and $A(\gamma)$. A household will choose to be active if $\gamma \leq \bar{\gamma}\left(s^{t}\right)$ where $\bar{\gamma}\left(s^{t}\right)$ is defined by:

$$
U\left(c_{A}\left(s^{t}\right)\right)-U\left(c_{I}\left(s^{t}, \bar{\gamma}\left(s^{t}\right)\right)\right)=U^{\prime}\left(c_{A}\left(s^{t}\right)\right)\left[c_{A}\left(s^{t}\right)-c_{I}\left(s^{t}, \bar{\gamma}\left(s^{t}\right)\right)+\bar{\gamma}\left(s^{t}\right)\right],
$$

and inactive otherwise. Equation (20) implies that there is a marginal household with fixed cost $\bar{\gamma}\left(s^{t}\right)$ whose net gain of rebalancing is equal to the cost of transferring funds across the two markets. The net gain, $U\left(c_{A}\left(s^{t}\right)\right)-U\left(c_{I}\left(s^{t}, \gamma\right)\right)$, is simply the difference in the level of utility from being active as opposed to inactive. The net cost of making the state-contingent transfer comprises the fee $\gamma$ and the amount transferred by the household, since $x\left(s^{t}, \gamma\right)=$ $c_{A}\left(s^{t}\right)-c_{I}\left(s^{t}, \gamma\right)$. In our context, the fixed cost of rebalancing leads to a state-dependent rule determining the fraction of households that reoptimize their portfolio allocations. With this rule, the resource constraint can be rewritten as:

$$
c_{A}\left(s^{t}\right) F\left(\bar{\gamma}\left(s^{t}\right)\right)+\int_{\bar{\gamma}\left(s^{t}\right)}^{\infty} c_{I}\left(s^{t}, \gamma\right) f(\gamma) d \gamma=\exp \left(\theta_{t}\right)-\int_{0}^{\bar{\gamma}\left(s^{t}\right)} \gamma f(\gamma) d \gamma,
$$

where $F(\gamma)$ is the cumulative distribution function for $\gamma$.

\subsubsection{Consumption of Rebalancers and the Equity Premium}

The asset pricing kernel in the economy depends on the consumption of the rebalancers and is given by:

$$
m\left(s^{t+1}\right)=\beta \frac{U^{\prime}\left[c_{A}\left(s^{t+1}\right)\right]}{U^{\prime}\left[c_{A}\left(s^{t}\right)\right]} .
$$

This pricing kernel is the state-contingent price of a security expressed in consumption units and normalized by the probabilities of the state. This pricing kernel can be used to determine the real risk-free rate $\left(r^{f}\right)$ as well as the real return on equity $\left(r^{e}\right)$. These returns are given by:

$$
\begin{gathered}
{\left[1+r^{f}\left(s^{t}\right)\right]^{-1}=\int_{s_{t+1}} m\left(s^{t}, s_{t+1}\right) g\left(s_{t+1} \mid s^{t}\right) d s_{t+1},} \\
1=\int_{s_{t+1}} m\left(s^{t}, s_{t+1}\right)\left[1+r^{e}\left(s^{t}, s_{t+1}\right)\right] g\left(s_{t+1} \mid s^{t}\right) d s_{t+1},
\end{gathered}
$$

where $g\left(s_{t+1} \mid s^{t}\right)=\frac{g\left(s^{t+1}\right)}{g\left(s^{t}\right)}$ denotes the probability of state $s_{t+1}$ conditional on state $s^{t}$. From equation (25) in the firm's problem, the equilibrium real return on equity is given by:

$$
1+r^{e}\left(s^{t+1}\right)=\frac{\left[\alpha \exp \left(\theta_{t+1}\right)+p_{k}\left(s^{t+1}\right)\right]}{p_{k}\left(s^{t}\right)} .
$$


Using these two equations, we can then define the equity premium in our economy as:

$$
\frac{\mathrm{E}_{t}\left[1+r_{t+1}^{e}\right]}{1+r_{t}^{f}}=1-\operatorname{cov}_{t}\left(m_{t+1}, 1+r_{t+1}^{e}\right),
$$

where for convenience we have switched notation to express both the expected return on equity and the covariance between the pricing kernel and the return on equity, which are both conditional on the state of the world at date $t$.

\subsection{Parameter Values and Numerical Solution}

A household's per-period preferences are given by:

$$
U(c)=\frac{c^{1-\sigma}}{1-\sigma},
$$

where $\sigma$ is the coefficient of constant relative risk aversion, which is set equal to 2 based on the survey of the literature in Hall (2008). The discount factor, $\beta=0.99$, is chosen to be consistent with a quarterly model, while the economy's capital share, $\alpha$, is 0.36 .

For the distribution of the fixed cost, $F(\gamma)$, we assume that there is some small positive mass of households with zero fixed costs and choose the remaining distribution, $1-F(0)$, to be lognormal so that $\log (\gamma) \sim N\left(\log \left(\gamma_{m}\right), \sigma_{m}^{2}\right)$. We set $F(0)=0.01, \gamma_{m}=0.045$, and $\sigma_{m}=0.35$, which imply that, on average, about 9 percent of households rebalance their portfolios in a quarter with some households rebalancing frequently and a large mass of households rarely rebalancing. As discussed in the introduction, such a calibration is broadly in line with the the micro evidence from the household finance literature discussed in the introduction.

In the model, absent the small average transaction cost, the aggregate consumption process corresponds to the technology shock. Therefore, we calibrated the parameters governing the process for technology based on the time series properties of aggregate consumption. We set $\rho_{z}=0.98$ and chose $\sigma_{z}=0.0085$ so that the standard deviation for annualized consumption growth is slightly higher than 3 percent, consistent with annual data on U.S. consumption over 1890-1993 from Campbell (1999). For the money growth process, we used quarterly data on M2 over the sample period 1959:Q1-2009:Q2 and estimated $\rho_{\mu}=0.68$ and $\sigma_{\mu}=0.007$. We set $\bar{\mu}=1.005$ so that average, annualized money growth rate is $2 \%$. 
The model is solved numerically using a global algorithm. We use Newton-Cotes quadrature to approximate the expectations associated with the normally-distributed technology and monetary shocks. As discussed in Judd (1999), the stochastic difference equation implied by equations (24) and (25) can then be used to determine the price of equity using linear Fredholm integral equations (Type 2). The function $A(\gamma)$ is approximated by solving the recursive representation of equation (19) exactly at a finite number of points and then using splines to approximate the function elsewhere.

\section{Results}

Before discussing the model's implications for monetary policy and the equity premium, it is helpful to characterize the non-stochastic steady state of the model.

\subsection{Deterministic Steady State}

In a deterministic environment with average money growth equal to $2 \%$ and output equal to unity, the endogenous rebalancing model reduces to a representative agent economy. This model only becomes interesting in the presence of uncertainty; nevertheless, it is useful to compare its deterministic steady state with the version of the model with endogenous participation.

In the non-stochastic steady state of the endogenous rebalancing model, all households will have the same level of consumption. According to equation (19), a household that chooses to be inactive obtains the same level of consumption as an active household. An inactive household can obtain such a level of consumption by choosing her initial plan such that $c_{A}=c_{I}=\frac{1-\alpha}{\mu}+A$, where $A$ takes on the same value across all inactive households. With consumption the same across households, all households with $\gamma>0$ will never rebalance their portfolios, and the households with $\gamma=0$ will be indifferent between rebalancing or using the non-state contingent transfer, $A$.

In the non-stochastic steady state of the endogenous participation model (i.e., $A(\gamma)=0$ for all $\gamma$ ), the consumption of active households exceeds the consumption of inactive households, 
who only receive $c_{I}=\frac{1-\alpha}{\mu}$. By choosing to be inactive, these agents do not receive the capital income associated with participating in the stock market. Accordingly, without a much larger fixed cost, there is a strong incentive for all households to participate in financial markets.

\subsection{Endogenous Rebalancing and the Equity Premium}

Figure 1 shows the sample averages for the risk-free rate and the equity premium (see the black dot labeled "U.S. Data") taken from Guvenen (2009). We also report 5\% confidence ellipse, based on his estimates. The figure also shows the average equity premium and risk-free rate in the endogenous rebalancing model using the benchmark calibration with $\sigma=2$. This calibration leads to an average equity premium of about $7 \%$ and a risk-free rate of $1.5 \%$.

Moving from southeast to northwest along the blue line with circles, each point reports the equity premium and risk-free rate for different values of $\gamma_{m}$, which leads to a different average fraction of rebalancers. There are two basic results that can be evinced from this line. First, decreasing the average fraction of rebalancers (by increasing $\gamma_{m}$ ) produces a rise in the equity premium and fall in the risk-free rate. Second, if the fraction of household rebalancers lies between roughly $8 \%$ and $13 \%$, then the model lies within the $95 \%$ confidence region. $^{9}$

The green line with squares in Figure 1 shows the results if we vary $\sigma$ in the endogenous rebalancing model. Raising the coefficient of relative risk aversion has a similar effect on the equity premium and risk-free rate as lowering the average fraction of rebalancers via $\gamma_{m}$. As the coefficient of relative risk aversion increases, the mean equity premium rises and the risk-free rate falls. For values of $\sigma$ between 1 and 2.5, the combination of mean returns on equity and the risk-free asset lies within the $95 \%$ confidence region. For comparison purposes, the magenta line with triangles in the southeast corner of the figure shows the results for the representative agent economy. In this model, as in Mehra and Prescott (1985), the only way to match the observed equity premium is to increase the coefficient of relative risk aversion to a high level.

\footnotetext{
${ }^{9}$ For the version of the model discussed in the appendix, which uses a discrete distribution over $\gamma$, we find a somewhat higher range of between $18 \%$ to $24 \%$ for the average fraction of rebalancers. See Table 1 in the appendix.
} 
The red line with diamonds shows the mean of the equity premium and risk-free rate for the endogenous participation model of Alvarez, Atkeson, and Kehoe (2009) for different values of $\gamma_{m}$. With the benchmark value of $\gamma_{m}=0.045$, the participation rate is close to 1 , the average equity premium is zero, and the real interest rate is about 4 percent. Raising $\gamma_{m}$ lowers the average participation rate in financial markets; however, there is little change in the average equity premium and real rate. Even if the participation rate is as low as $15 \%\left(\gamma_{m}=2.5\right)$, the average equity premium and real rate lie well outside the ellipse.

With $\gamma_{m}=0.045$ in the benchmark calibration of the endogenous rebalancing model, the average household rebalancing cost is relatively small - less than 0.2 percent of average household consumption. In contrast, in the endogenous participation model, large values of $\gamma_{m}$ are necessary to induce reasonable rates of stock market participation. For example, a value of $\gamma_{m}=0.5$ implies that the average participation rate is $40 \%$, and the average participation cost is more than $15 \%$ of average consumption.

Since the only difference between the endogenous rebalancing and participation models is the presence of the non-state contingent transfer plan $A(\gamma)$, Figure 1 demonstrates the critical role that this variable plays in the analysis. The top panel of Figure 2 also shows that the demand for this transfer plan is increasing in a household's fixed cost. The function is increasing, because a household with a higher fixed cost anticipates that she will rebalance her portfolio allocation less frequently and therefore demand a larger value of $A(\gamma)$ to help ensure against consumption losses.

The transfer plan helps account for the level of the equity premium by driving up the volatility of active consumption. The middle panel of Figure 2 shows the standard deviation of consumption for different types of households in the endogenous rebalancing model. The consumption volatility of a household that frequently rebalances is about 4 times greater than a household that keeps its portfolio unchanged from her initial plan. This higher volatility of consumption for active households leads to a higher positive covariance between the return on equity and active consumption growth, which then translates into a higher average equity premium via expression (26). 
The implication of the model regarding the consumption volatility of different household types appears to be in line with recent evidence provided by Parker and Vissing-Jorgensen (2009). Using data from the Consumer Expenditure (CEX) Survey, they found that the consumption of 'high-consumption' households is more exposed to fluctuations in aggregate consumption (and income) than that of low-consumption households. In particular, they found that the exposure to changes in aggregate consumption growth of households in the top 10 percent of the consumption distribution is about five times that of households in the bottom 80 percent.

The lower panel of Figure 2 indicates that active households have a higher level of consumption than inactive households. In effect, households that rebalance more frequently are trading off higher consumption volatility against a higher level of consumption. The consumption of active households is more volatile than the consumption of inactive households, because the two aggregate shocks only affect the consumption of the latter type of household through changes in labor income, while active households experience fluctuations in both labor and capital income. Later, we develop the intuition of this result more formally using a version of the model in which $A(\gamma)$ is assumed to be the same for all households.

\subsection{Monetary Policy and Equity Prices}

In the endogenous rebalancing model, monetary policy shocks can induce important fluctuations in equity prices and the equity premium. In this section, we investigate this relationship and compare our model's implications to the estimates of Bernanke and Kuttner (2005).

Using high-frequency data on the federal funds rate, Bernanke and Kuttner (2005) construct a measure of unanticipated changes in monetary policy. They find that a broad index of stock prices registers a gain of 1 percent in reaction to a 25 basis point easing of the federal funds rate. Bernanke and Kuttner (2005) then use monthly data with a structural VAR to decompose the response of stock prices into three components: changes in current and expected future dividends, changes in current and expected future real interest rates, and changes in expected future excess equity returns or equity premia. While an unanticipated easing lowers interest rates, they conclude that an important channel in which increases in stock prices occur is 
through changes in equity premia or the perceived riskiness of stocks.

To compare the model's implications to their empirical results, we compute impulse response functions. Since the model is nonlinear, it is important to define how we construct these impulse responses. Follow the discussion in Hamilton (1994), we define the impulse response of variable, $y\left(s^{t}\right)$, at date $t$ to a monetary innovation that occurs at date 1 as:

$$
E\left[\log \left(y\left(s^{t}\right)\right) \mid \epsilon_{\mu 1}, \mu_{0}, z_{0}\right]-E\left[\log \left(y\left(s^{t}\right)\right) \mid \mu_{0}, z_{0}\right], \forall t \geq 1
$$

Thus, an impulse response is defined as the revision in expectations after a shock that occurs at date 1. For log-linear models, equation (28) simplifies to the usual analytical representation in which (up to a scaling factor) the model's linear coefficients characterize the impulse response function.

Figure 3 shows the impulse response of different economic variables to a decline in money growth. In the endogenous rebalancing model (the solid black line), the nominal interest rate increases 50 basis points on impact, and the real rate increase about 1 percentage point. Thus, as in the limited participation models of Lucas (1990), Fuerst (1992), and Alvarez, Atkeson, and Kehoe (2002), the economy displays a liquidity effect. Moreover, the effect is persistent, as interest rates gradually fall back to their pre-shocked level. In line with Bernanke and Kuttner (2005), equity prices fall about 1 percent on impact, with much of the decline reflecting a higher equity premium. On impact, the equity premium rises more than 1 percentage point, and its response mirrors that of equity prices. ${ }^{10}$

To understand why the model generates a sharp rise in the equity premium, the bottom left panel of Figure 3 shows the response of consumption of active households (rebalancers). The monetary contraction has no effect on output but has an important redistributive effect. It raises the consumption of non-active households, whose real money balances available for consumption increase, and lowers the consumption of those that choose to rebalance. This redistributive effect provides households with less incentive to rebalance their portfolios, which reduces the degree of risk-sharing amongst active households and helps push up the equity premium.

\footnotetext{
${ }^{10}$ The increase in stock prices also reflects the decline in real rates. Dividends in our model are simply a function of technology and do not change in response to the monetary innovation.
} 
The blue dashed line shows the effects of the same increase in money growth in the endogenous participation model of Alvarez, Atkeson, and Kehoe (2009). This model does not generate a liquidity effect and there is very little movement in the equity premium. Accordingly, variation along the intensive margin (i.e., the frequency of rebalancing between checking and brokerage accounts) appears to be a more fruitful way of generating movements in the equity prices than the extensive margin (i.e., the number of financial market participants).

\subsection{Understanding the Mechanism}

To understand how endogenous changes in the number of rebalancers can induce time-varying movements in risk, it is helpful, for illustrative purposes, to assume that $A(\gamma)=A \forall \gamma$ where $A$ is given and that $\gamma$ is distributed according to a continuous, uniform distribution with $\gamma \in\left[0, \gamma_{J}\right]$. Under these conditions, the model has a unique and closed form solution when $\sigma=2$. In particular, equation (20) can be rewritten as:

$$
\left(c_{A}-c_{I}\right)^{2}=c_{I} \bar{\gamma}
$$

and the resource constraint can be rewritten as:

$$
\frac{\bar{\gamma}}{\gamma_{J}} c_{A}+\left(1-\frac{\bar{\gamma}}{\gamma_{J}}\right) c_{I}=(1-\alpha) \exp (\theta)-\frac{\bar{\gamma}^{2}}{2 \gamma_{J}}
$$

where $c_{I}=\frac{(1-\alpha) \exp (\theta)}{\mu}+A \cdot{ }^{11}$ Equation (29) characterizes the marginal household's decision to rebalance its portfolio (i.e., the type $\bar{\gamma}$ household). We call the schedule of the combination of values of $\bar{\gamma}$ and $c_{A}$ the MR curve in reference to the marginal rebalancer. The top panel of Figure 4 shows that this curve is a parabola with a minimum occurring at $c_{I}$. For $c_{A}>c_{I}$, the state-contingent transfer of an active household (i.e., $x=c_{A}-c_{I}$ ) is positive, as is the cost of transferring funds. A rise in the consumption of active households, all else equal, makes it more attractive to make the state contingent transfer, and thus for $c_{A}>c_{I}$, the MR schedule is increasing.

\footnotetext{
${ }^{11}$ Given our assumptions, the equations determining the equilibrium are static, and we simplify our notation, ignoring that these variables depend on $s^{t}$.
} 
The second equation represents the combination of values of $c_{A}$ and $\bar{\gamma}$ that satisfy goods market clearing, and can be used to express the fraction of rebalancers (i.e., $\frac{\bar{\gamma}}{\gamma_{J}}$ ) as a function of their consumption. We call this schedule the GM curve for goods market clearing. For $c_{A}>c_{I}$ where $c_{I}=\frac{1-\alpha}{\mu}+A$, the top panel of Figure 4 shows that this curve is downward sloping. This reflects that an increase in $\gamma$ raises the average level of transaction costs in the economy, reducing real resources, and lowering the consumption of rebalancers.

Figure 4 displays the equilibrium in the endogenous rebalancing model as the intersection of these two curves. In the endogenous rebalancing model, this intersection occurs at a point in which $c_{A}>c_{I}$, though consumption of a rebalancer is not much higher than the consumption of a non-rebalancer, reflecting $A>0$. In contrast, the bottom panel of Figure 4 shows that the equilibrium in the endogenous participation model $(A=0)$ occurs at a point in which active consumption is much higher than inactive consumption (given by the vertex of the parabola). The equilibrium financial market participation rate shown in the bottom panel is also much higher than the rate of rebalancing that occurs in equilibrium in the top panel.

\subsubsection{Technology Shocks}

This difference in the equilibrium positions of the two economies has important implications for the volatility of the consumption of active households and therefore the equity premium. To demonstrate this using our illustrative example, the upper panel of Figure 5 displays the effects of a deterministic increase in technology on the equilibrium allocations implied by equations (29) and (30). An increase in technology shifts the GM curve upward and to the right, as the economy's resources expand. The MR curve shifts to the right, as the wage income of non-rebalancers rises. This boosts the consumption of non-rebalancers from $c_{I 0}$ to $c_{I 1}$.

With the initial equilibrium occurring near the minimum of the parabola, there is a large increase in the consumption of rebalancers that exceeds both the increase in non-rebalancer consumption and technology. This large increase reflects that the technology shock, by raising the return on equity, also involves a redistribution away from non-rebalancers to rebalancers. While this redistribution occurs in the endogenous participation model, its effects on active 
consumption are modest, given that the initial equilibrium is at a point at which the MR curve is relatively steep. Accordingly, Figure 5 demonstrates that active consumption in the endogenous rebalancing model will be considerably more volatile than active consumption in the participation model.

\subsubsection{Monetary Policy Shocks}

To understand why a monetary contraction induces an increase in the equity premium, it is helpful to consider the effect of a deterministic change in money growth on the GM and MR schedules. The lower panel of Figure 5 shows the effects of a small decrease in the money growth rate. This decrease shifts the GM curve to the left, since the consumption of rebalancers falls for a fixed $\bar{\gamma}$. In addition, higher consumption of the non-rebalancers (which occurs at the minimum of the parabola) shifts the MR curve downward and to the right, implying that the benefit to making the state-contingent transfer has gone down. Hence, the deterministic fall in money growth leads to an equilibrium with both lower consumption of active rebalancers and a smaller fraction of rebalancers.

With the decrease in money growth occurring from an initial equilibrium close to the minimum of the parabola, a small monetary contraction may induce a relatively large fall in the consumption of rebalancers. However, this effect diminishes as the monetary shock becomes larger, reflecting the concavity of the MR schedule. Near the initial equilibrium, small declines in monetary growth induce relatively large decreases in consumption, while larger declines have a proportionately smaller effect on consumption.

Building on this analysis, the top two panels of Figure 6 show the first and second derivatives of the logarithm of active consumption with respect to the logarithm of money growth. The top panel shows that the first derivative (i.e., $\left.\frac{\partial \log c_{A}\left(\mu_{t}\right)}{\partial \log \mu_{t}}\right)$ is positive and decreasing, reflecting that higher money growth boosts active consumption but by progressively less. The middle panel shows that the second derivative is a large, negative number, reflecting the high degree of concavity of active consumption. In addition, the second derivative is increasing in money growth, implying that larger increases in money growth have a proportionately smaller effect on 
risk.

This nonlinearity drives the endogenous fluctuations in risk in our model. An increase in money growth reduces the sensitivity of active consumption to expected future changes in money growth, as the fraction of active rebalancers increases. Thus, for higher rates of money growth, active consumption growth becomes less volatile and its covariance with the return on equity diminishes, leading to a decline in the equity premium.

\section{Conclusions}

We have developed a dynamic stochastic general equilibrium model in which aggregate shocks affect the economy through movements in risk. Our model is an extension of a neoclassical framework in which asset and goods markets are segmented from each other. We view this model as the next link in the chain beginning with Lucas (1990) and recently extended by Alvarez, Atkeson, and Kehoe (2002). We depart from the former in two important respects. First, we explicitly model a production economy with equity returns. Second, we emphasize endogenous asset segmentation along an intensive margin (i.e., portfolio rebalancing decision) rather than along an extensive margin (i.e., participation decision). Through this mechanism, we are able to account for the average excess returns on equity, countercyclical movements in risk, and, in line with the evidence of Bernanke and Kuttner (2005), a monetary easing can lead to a decline in the equity premium.

A natural extension of this paper will be to incorporate endogenous capital and labor supply considerations to examine whether the model can account for key features of both asset prices and business cycles. 


\section{References}

Abel, A. B., J. C. Eberly, and S. Panageas (2007). Optimal Inattention to the Stock Market and Information Costs and Transaction Costs. mimeo, Wharton School of the University of Pennsylvania.

Alvarez, F., A. Atkeson, and P. Kehoe (2007). If Exchange Rates are Random Walks, Then Almost Everything we Say About Monetary Policy is Wrong. American Economic Review 97, 339-345.

Alvarez, F., A. Atkeson, and P. Kehoe (2009). Time-Varying Risk, Interest Rates, and Exchange Rates in General Equilibrium. The Review of Economic Studies. forthcoming.

Alvarez, F., A. Atkeson, and P. J. Kehoe (2002). Money, Interest Rates, and Exchange Rates with Endogenously Segmented Markets. Journal of Political Economy 110, 73-112.

Ameriks, J. and S. P. Zeldes (2004). How Do Household Portfolio Shares Vary with Age? mimeo, Columbia University.

Bacchetta, P. and E. van Wincoop (2009). Infrequent Portfolio Decisions: A Solution to the Forward Discount Puzzle. American Economic Review. Forthcoming.

Bernanke, B. and K. Kuttner (2005). What Explains the Stock Markets Reaction to Federal Reserve Policy? Journal of Finance LX, 1221-1257.

Bilias, Y., D. Georgarakos, and M. Haliassos (2008). Portfolio Inertia and Stock Market Fluctuations. CFS Working Paper 2006/4. Revised July 2008.

Boldrin, M., L. J. Christiano, and J. D. Fisher (1997). Habit Persistence and Asset Returns in an Exchange Economy. Macroeconomic Dynamics 1, 312-332.

Bonaparte, Y. and R. Cooper (2009). Costly Portfolio Adjustment. National Bureau of Economic Research Working Paper 15227.

Brunnermeier, M. and S. Nagel (2008). Do Wealth Fluctuations Generate Time-Varying Risk Aversion? Micro-Evidence from Individuals Asset Allocation. American Economic Review 98, 713-736.

Calvet, L. E., J. Y. Campbell, and P. Sodini (2009a). Fight or Flight? Portfolio Rebalancing by Individual Investors. Quarterly Journal of Economics 124, 301-348.

Calvet, L. E., J. Y. Campbell, and P. Sodini (2009b). Measuring the Financial Sophistication of Households. American Economic Review 99, 393-398.

Campbell, J. Y. (1999). Asset Prices, Consumption, and the Business Cycle. In J. B. Taylor and M. Woodford (Eds.), Handbook of Macroeconomics. North-Holland, Amsterdam.

Fuerst, T. S. (1992). Liquidity, Loanable Funds, and Real Activity. Journal of Monetary Economics 29, 3-24.

Gabaix, X. and D. Laibson (2001). The 6D Bias and the Equity-Premium Puzzle. In B. Bernanke and J. Rotemberg (Eds.), NBER Macroeconomics Annual. MIT Press. 
Gomes, F. and A. Michaelides (2006). Asset Pricing with Limited Risk Sharing and Heterogeneous Agents. mimeo, London School of Economics.

Gust, C. and D. López-Salido (2009). Monetary Policy, Velocity, and the Equity Premium. Centre for Economic Policy Research Discussion Paper No. 7388.

Guvenen, F. (2005). A Parsimonious Macroeconomic Model for Asset Pricing: Habit Formation or Cross-sectional Heterogeneity? mimeo, University of Rochester.

Guvenen, F. (2009). A Parsimonious Macroeconomic Model for Asset Pricing. Econometrica. forthcoming.

Hall, R. (2008). Sources and Mechanisms of Cyclical Fluctuations in the Labor Market. mimeo, Stanford University.

Hamilton, J. D. (1994). Time Series Analysis. Princeton, NJ: Princeton University Press.

Judd, K. L. (1999). Numerical Methods in Economics. Cambridge, MA: The MIT Press.

Lucas, R. E. (1990). Liquidity and Interest Rates. Journal of Economic Theory 50, 237-264.

Lynch, A. (1996). Decision Frequency and Synchronization Across Agents: Implications for Aggregate Consumption and Equity Returns. Journal of Finance LI, 1479-1497.

Marshall, D. and N. Parekh (1999). Can Costs of Consumption Adjustment Explain Asset Pricing Puzzles? Journal of Finance LIV, 623-654.

Mehra, R. and E. Prescott (1985). The Equity Premium Puzzle. Journal of Monetary Economics 15, 145-166.

Parker, J. and A. Vissing-Jorgensen (2009). Who Bears Aggrgate Fluctuations and How? American Economic Review 99, 399-405.

Polkovnichenko, V. (2004). Limited Stock Market Participation and the Equity Premium. Finance Research Letters 1, 24-34.

Reis, R. (2006). Inattentive Consumers. Journal of Monetary Economics 53, 1761-1800.

Souleles, N. S. (2003). Household Portfolio Choice, Transactions Costs, and Hedging Motives. mimeo, University of Pennsylvania.

Vissing-Jorgensen, A. (2002). Towards an Explanation of Household Portfolio Choice Heterogeneity: Non-Financial Income Participation Costs Structures. National Bureau of Economic Research Working Paper 8884.

Vissing-Jorgensen, A. (2003). Perspectives on Behavioral Finance: Does Irrationality Disappear with Wealth? Evidence from Expectations and Actions. In M. Gertler and K. Rogoff (Eds.), NBER Macroeconomics Annual. MIT Press. 
Figure 1: Endogenous Rebalancing and the Equity Premium

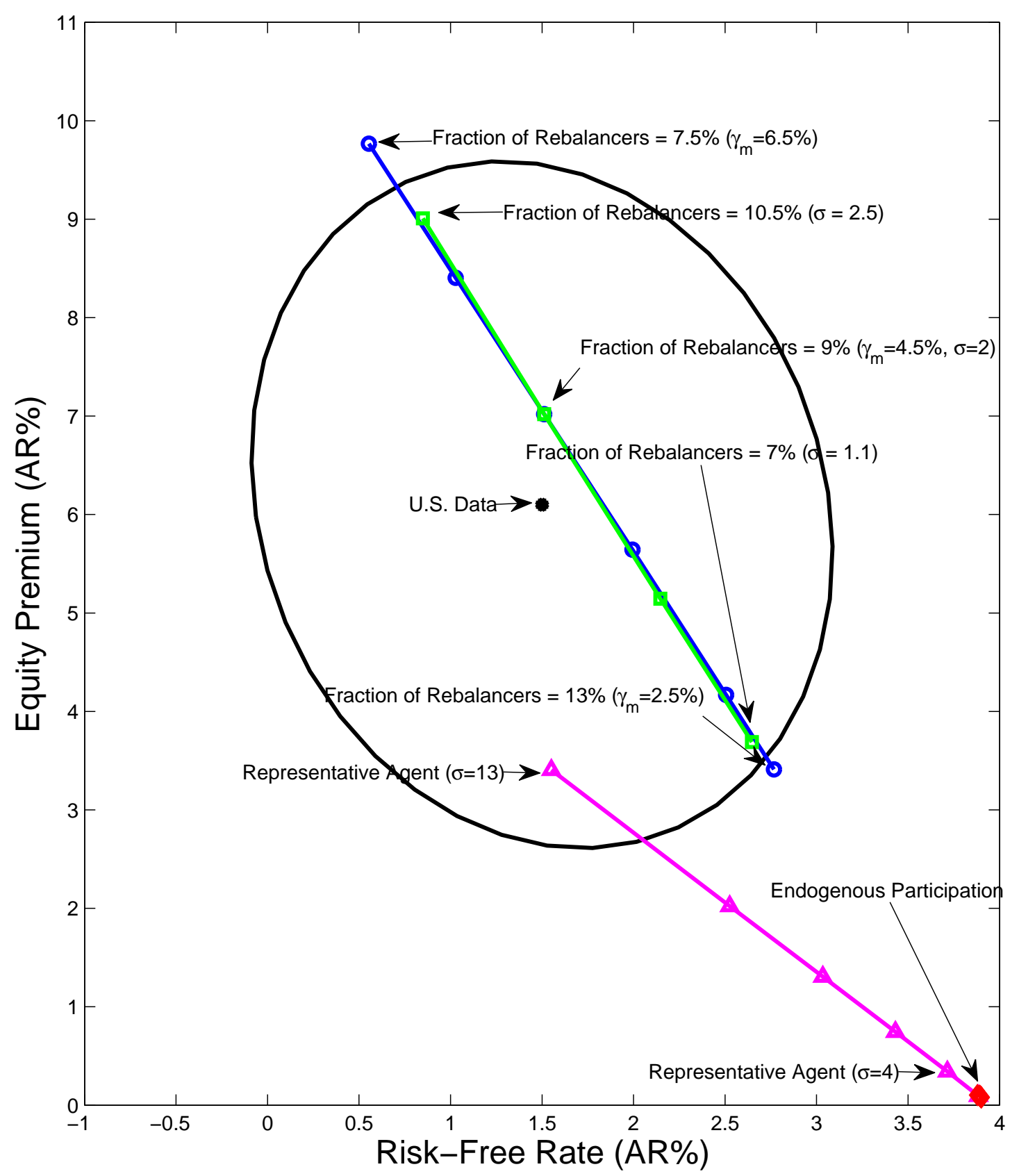


Figure 2: The Non-State Contingent Transfer Plan and Consumption Across Households

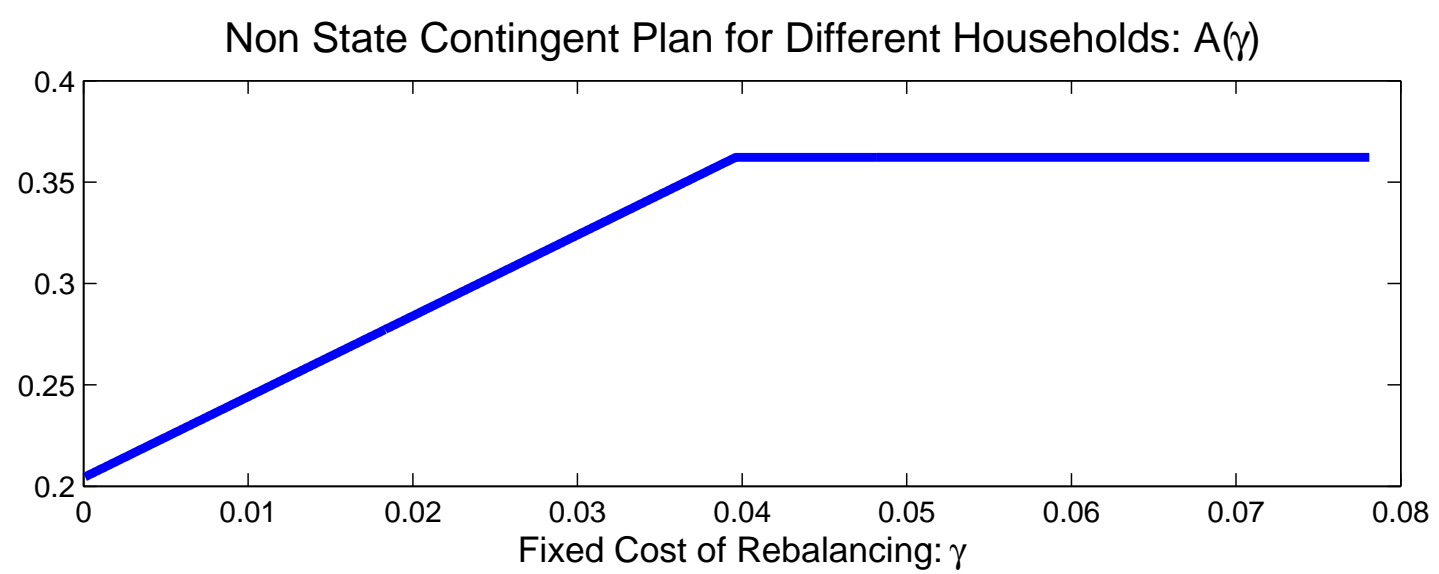

Standard Deviation of Individual Consumption Relative to Aggregate

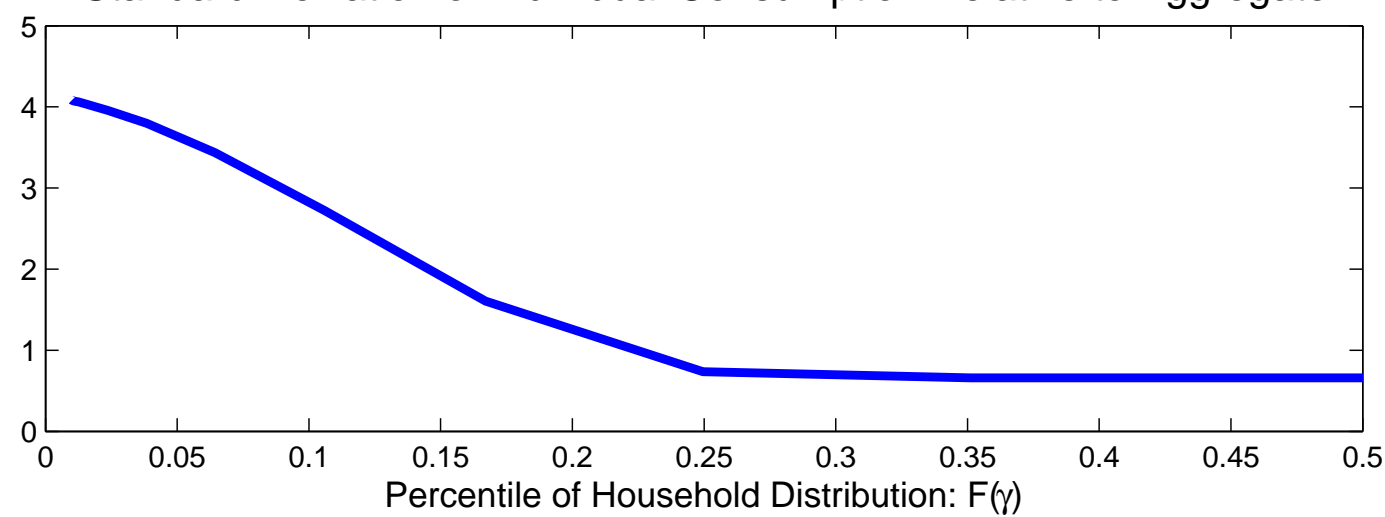

Average Consumption

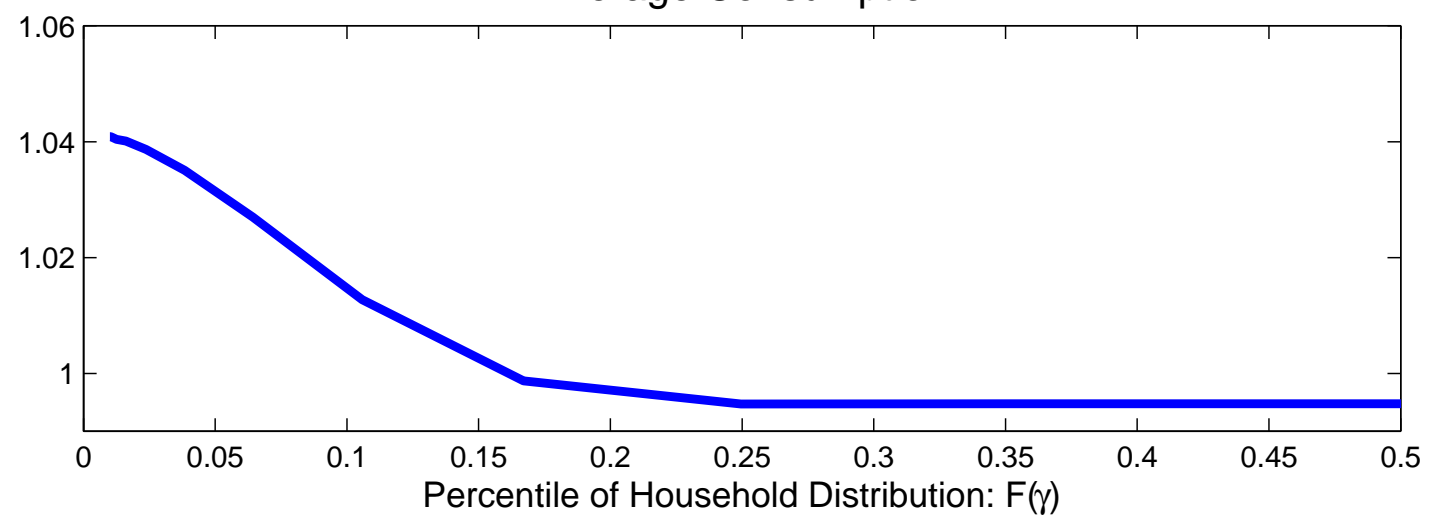


Figure 3: Impulse Response to a Contractionary Monetary Shock (Deviation from Date 0 Expectation of a Variable)
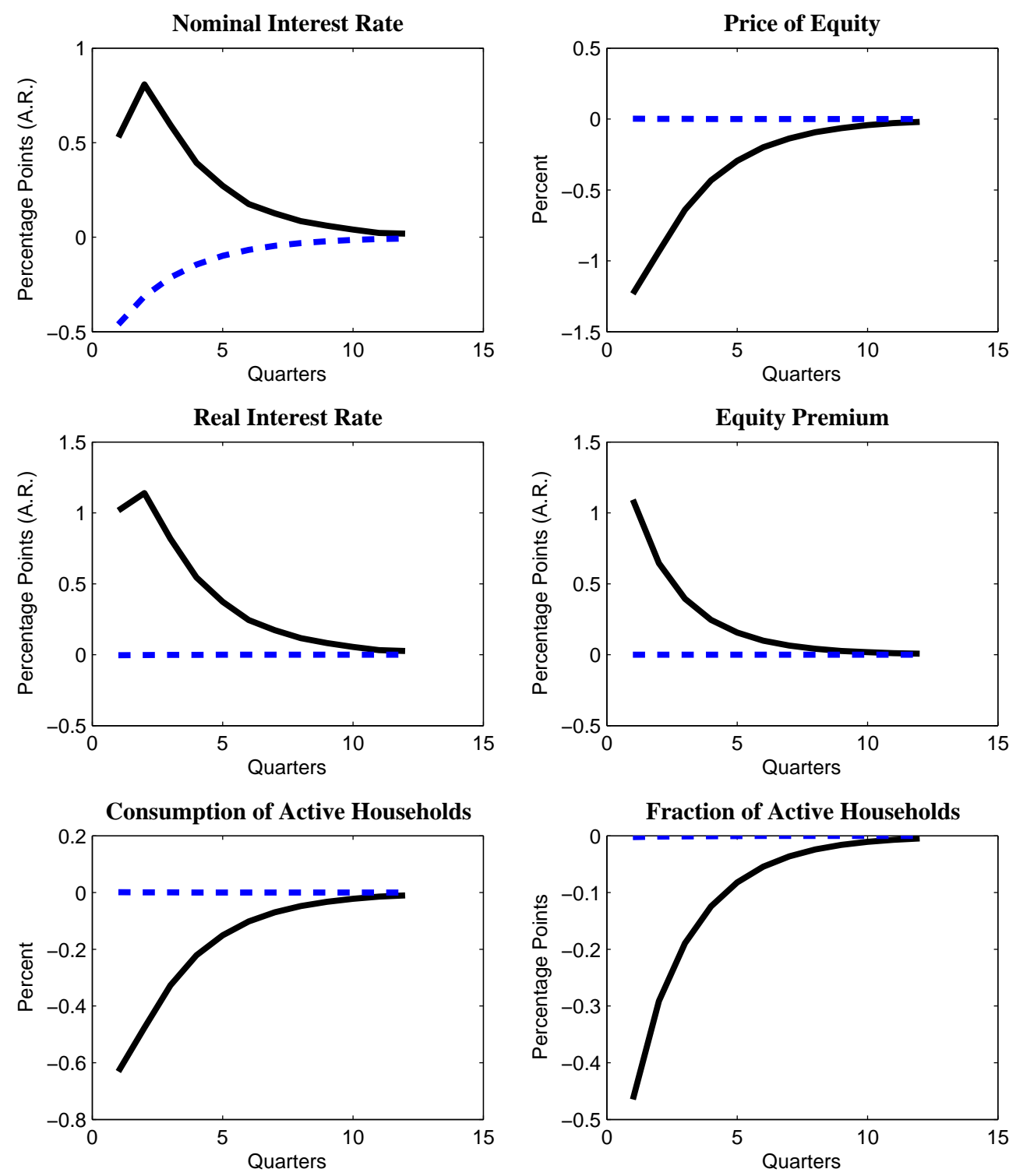

Endogenous Rebalancing: $A(\gamma)>0$

- - - Endogenous Participation: $\mathrm{A}(\gamma)=0$ 
Figure 4: Equilibrium in the Two Models
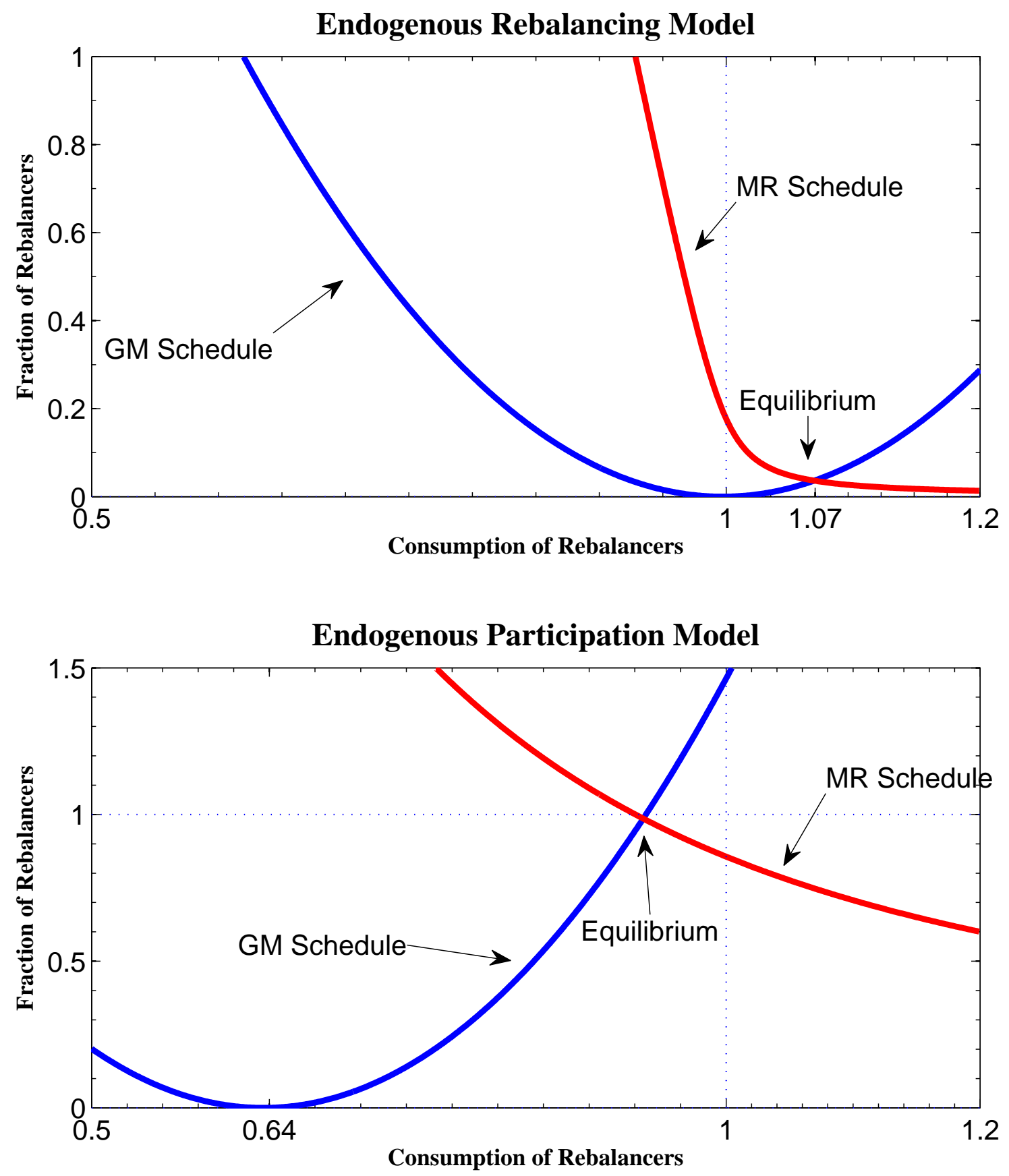
Figure 5: Deterministic Changes in the Rebalancing Model

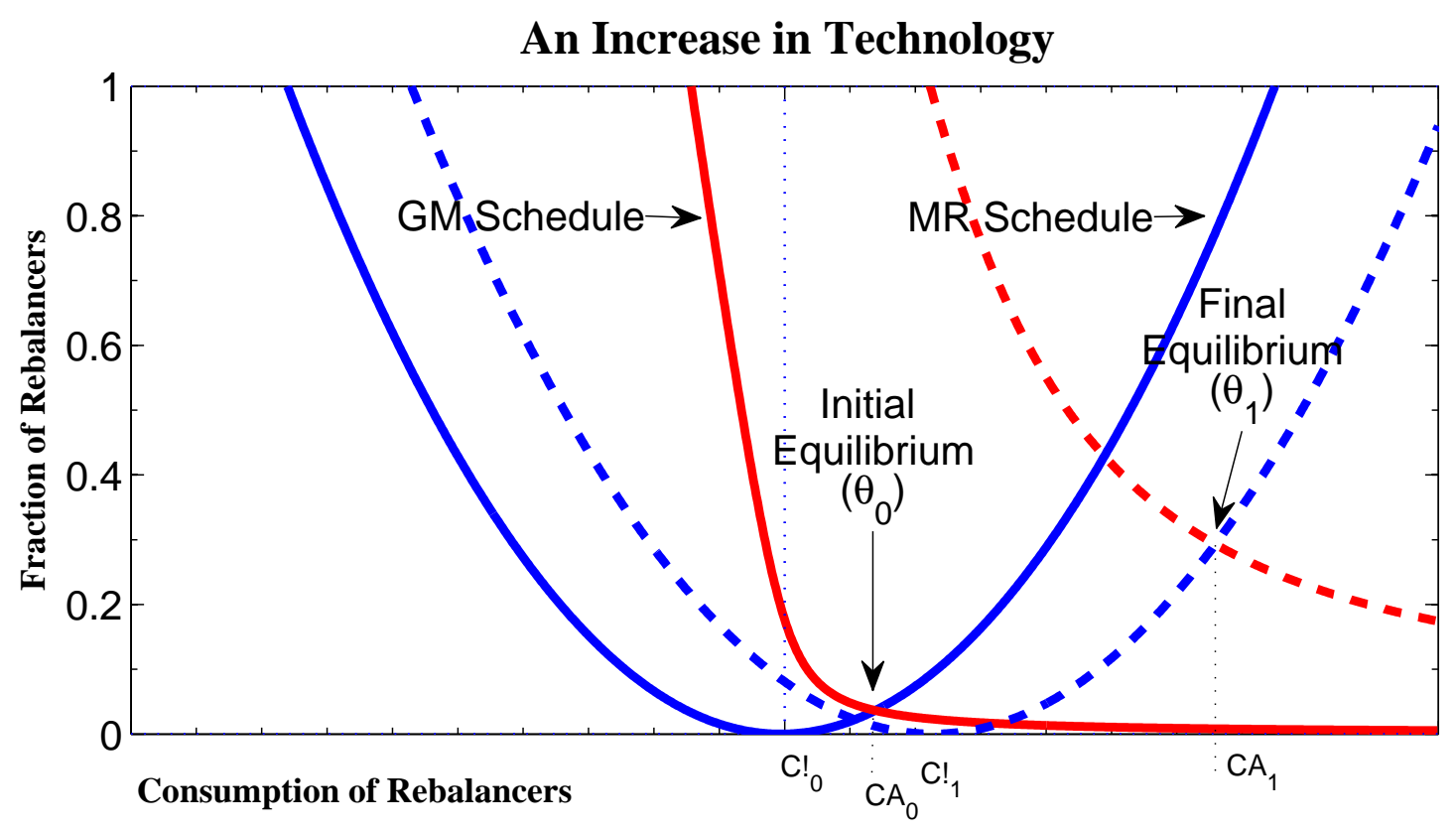

A Monetary Contraction

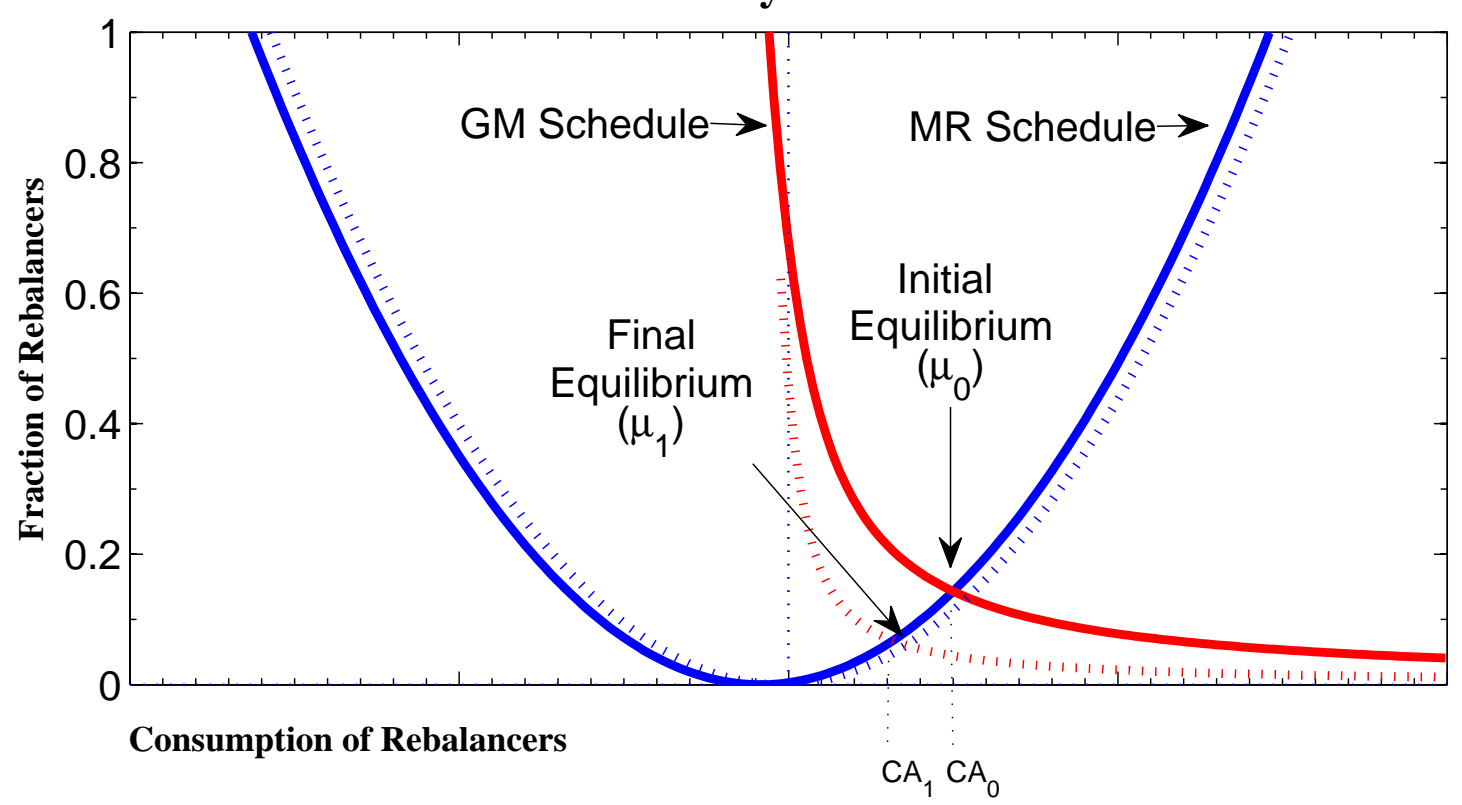


Figure 6: The Shape of Active Consumption Elasticity of Consumption With Respect to Money Growth

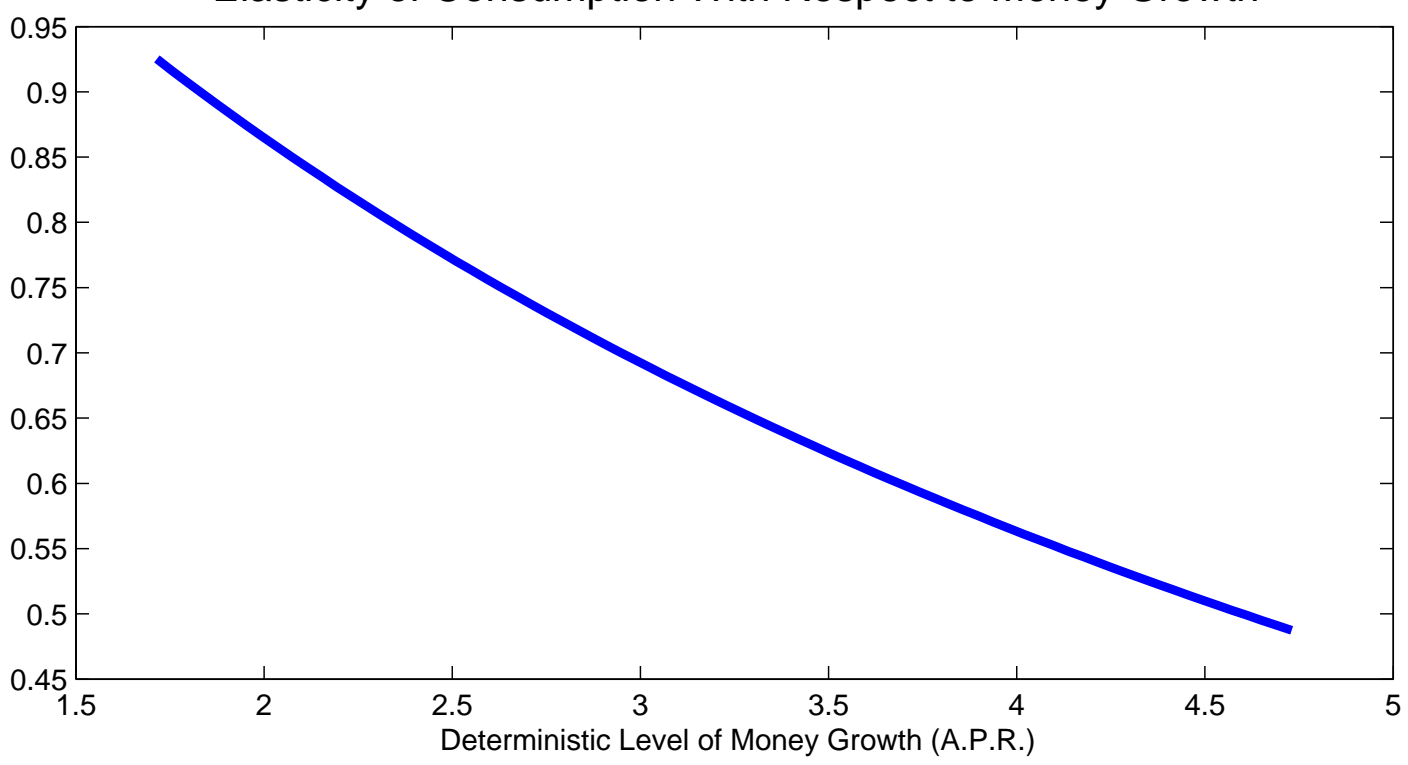

Second Derivative of Consumption With Respect to Money Growth

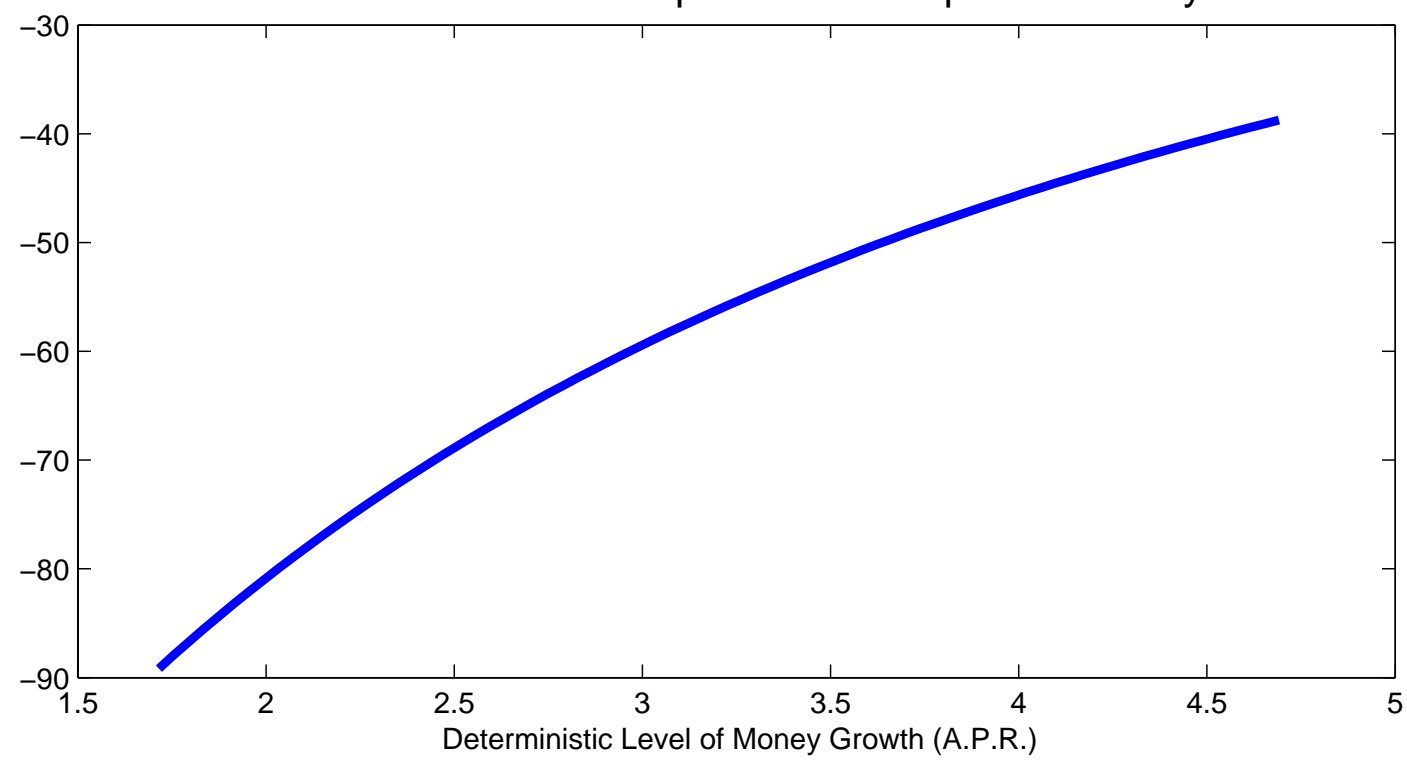




\section{A Appendix}

In this appendix, we briefly describe how the model is modified to incorporate occasionally binding cash constraints for households. We then compare selected model statistics for the endogenous rebalancing model to the endogenous participation model when these constraints only bind occasionally. Gust and López-Salido (2009) provide a more detailed treatment of this version of the model and its implications.

To incorporate the possibility that a household may choose to save cash in its brokerage account, we denote $N\left(s^{t}, \gamma\right)$ as cash saved for transactions next period and rewrite a household's flow of funds in her brokerage account at date 0 as:

$$
\bar{B}(\gamma)=S\left(s^{0}, \gamma\right)+\int_{s_{1}} q\left(s^{1}\right) B\left(s^{1}\right) d s_{1}+N\left(s^{0}, \gamma\right)
$$

A household's flow of funds in her brokerage account at future dates is given by:

$$
\begin{gathered}
B\left(s^{t}, \gamma\right)+\left(1+R^{e}\left(s^{t}\right)\right) S\left(s^{t-1}, \gamma\right)+N\left(s^{t-1}, \gamma\right)=S\left(s^{t}, \gamma\right)+N\left(s^{t}, \gamma\right)+P\left(s^{t}\right) A(\gamma)+ \\
\int_{s_{t+1}} q\left(s^{t}, s_{t+1}\right) B\left(s^{t}, s_{t+1}, \gamma\right) d s_{t+1}+P\left(s^{t}\right)\left[x\left(s^{t}, \gamma\right)+\gamma\right] z\left(s^{t}, \gamma\right)
\end{gathered}
$$

Each household will choose not to store excess cash in its brokerage account if the nominal interest rate, $i\left(s^{t}\right)$, is positive, where the nominal interest rate is given by:

$$
1+i\left(s^{t}\right)=\frac{U^{\prime}\left(c_{A}\left(s^{t}\right)\right)}{\beta \int_{s_{t+1}} U^{\prime}\left(c_{A}\left(s^{t+1}\right)\right) \frac{g\left(s_{t+1} \mid s^{t}\right)}{\pi\left(s^{t+1}\right)} d s_{t+1}} .
$$

If the nominal interest rate reaches its zero lower bound (ZLB), then households may carry excess cash in their brokerage accounts. In this case, the ZLB constraint can be used to determine an equilibrium value for $N\left(s^{t}\right)=N\left(s^{t}, \gamma\right), \forall \gamma$, as each household faces the same first order condition regarding its choice of $N\left(s^{t}, \gamma\right)$.

A household may also choose to save extra cash in her checking account as a form of precautionary savings. In this case, we can rewrite a household's evolution of cash in her checking account as:

$$
P\left(s^{t}\right) c\left(s^{t}, \gamma\right)=M\left(s^{t-1}, \gamma\right)+P\left(s^{t}\right) x\left(s^{t}, \gamma\right) z\left(s^{t}, \gamma\right)+P\left(s^{t}\right) A(\gamma)-P\left(s^{t}\right) a\left(s^{t}, \gamma\right)
$$

where $a\left(s^{t}, \gamma\right)$ denotes excess cash used for future consumption instead of consumption today. Thus, a household's cash in her checking account at the end of period $t$ is given by:

$$
M\left(s^{t}, \gamma\right)=P\left(s^{t}\right)\left[w\left(s^{t}\right)+a\left(s^{t}, \gamma\right)\right] .
$$

A household will not carry excess cash in its checking account if:

$$
\frac{\left.U^{\prime}\left(c_{A}\left(s^{t}\right)\right) z\left(s^{t}, \gamma\right)+U^{\prime}\left(c_{I}\left(s^{t}, \gamma\right)\right)\left(1-z\left(s^{t}, \gamma\right)\right)\right)}{\beta \int_{s_{t+1}}\left[U^{\prime}\left(c_{A}\left(s^{t+1}\right)\right) z\left(s^{t+1}, \gamma\right)+U^{\prime}\left(c_{I}\left(s^{t+1}, \gamma\right)\right)\left(1-z\left(s^{t+1}, \gamma\right)\right)\right] \frac{g\left(s_{t+1} \mid s^{t}\right)}{\pi\left(s^{t+1}\right)} d s_{t+1}}>1 .
$$


This condition states that in states of the world in which consumption is low relative to expected discounted future consumption a household will not save excess cash but use it for consumption today. However, this condition can be violated in states of the world in which a household's consumption today is high. In that case, equation (A.6) will hold as a strict equality and can be used to determine a household's excess cash, $a\left(s^{t}, \gamma\right)>0$. For a household that always rebalances, equation (A.6) simplifies to $i\left(s^{t}\right)>0$, and for such a household carrying excess cash in their checking account is irrelevant.

In equation (A.6), the consumption of an inactive household needs to reflect that she may hold excess cash in her checking account:

$$
c_{I}\left(s^{t}, \gamma\right)=\frac{(1-\alpha) \exp \left(\theta_{t-1}\right)+a\left(s^{t-1}, \gamma\right)}{\pi\left(s^{t}\right)}+A(\gamma)-a\left(s^{t}, \gamma\right)
$$

while consumption of active households still satisfies equation (18), which equates consumption across active households. In equilibrium, inflation now must reflect that velocity is non-constant so that

$$
\pi\left(s^{t}\right)=\mu_{t} \frac{\mu_{v}\left(s^{t}\right)}{\mu_{y}\left(s^{t}\right)}
$$

where $\mu_{y}\left(s^{t}\right)=\frac{Y\left(s^{t}\right)}{Y\left(s^{t-1}\right)}, \mu_{v}\left(s^{t}\right)=\frac{V\left(s^{t}\right)}{V\left(s^{t-1}\right)}$, and

$$
V\left(s^{t}\right) \equiv \frac{P\left(s^{t}\right) Y\left(s^{t}\right)}{M_{t}}=\frac{Y\left(s^{t}\right)}{Y\left(s^{t}\right)+\sum_{j=1}^{J}\left[a\left(s^{t}, \gamma_{j}\right)+N\left(s^{t}, \gamma_{j}\right)\right] f\left(\gamma_{j}\right)} .
$$

The expression for velocity implies that in states of the world in which all households do not store excess cash, velocity will be a constant equal to unity. However, velocity will be less than one in states in which one or more household chooses to hold excess cash.

In the above expression for velocity, we have modified the distribution of household types, $f(\gamma)$ so that it is discrete where $\gamma \in\left[\gamma_{1}, \gamma_{2}, \ldots, \gamma_{J}\right] .{ }^{12}$ This assumption reflects that with each household potentially holding excess cash, there are as many state variables in the model as household types. Accordingly, we use a discrete distribution of types to help avoid the "curse of dimensionality". With a discrete number of household types, there is not necessarily a marginal household satisfying equation (20). Instead, a household with type $\gamma$ will choose to be active if:

$$
U\left(c_{A}\left(s^{t}\right)\right)-U\left(c_{I}\left(s^{t}, \gamma\right)\right)-U^{\prime}\left(c_{A}\left(s^{t}\right)\right)\left[c_{A}\left(s^{t}\right)-c_{I}\left(s^{t}, \gamma\right)+\gamma\right] \geq 0
$$

and inactive otherwise.

The second column of Table 1 shows selected statistics from the endogenous rebalancing model with three types of households: one that always rebalances $\left(\gamma_{1}=0\right)$, another that frequently rebalances $\left(\gamma_{2}=0.02\right)$, and a type that rarely rebalances $\left(\gamma_{3}=0.04\right) .{ }^{13}$ These

\footnotetext{
${ }^{12}$ To derive the expression for velocity, we used the resource constraint, a household's cash constraint in her checking account, and the money market clearing condition modified to incorporate excess cash holdings by households.

${ }^{13}$ For this calibration, we also assumed that the technology and monetary shock are governed by finite-state, symmetric Markov chains that are designed to well approximate AR(1) processes. See Gust and López-Salido (2009) for details.
} 
three types are distributed so that there are a large mass of households who rarely rebalance $\left(f\left(\gamma_{3}\right)=0.712\right)$, a moderate mass of frequent rebalancers $\left(f\left(\gamma_{2}\right)=0.22\right)$, and a smaller mass of households that always rebalance $\left(f\left(\gamma_{1}\right)=0.068\right)$. As shown in Table 1 , this calibration implies that 20 percent of households rebalance their portfolios in a quarter and as discussed in the introduction is broadly in line with the micro evidence from the household finance literature that provides strong support for infrequent portfolio rebalancing.

While the average fraction of households that rebalance in a quarter is somewhat higher than when the households are distributed log-normally, the average equity premium and average risk-free rate at $5.4 \%$ and and $0.7 \%$, respectively, are well within the confidence ellipse shown in Figure 1. Households that never rebalance $\left(\gamma_{1}\right)$ and households that rarely rebalance $\left(\gamma_{3}\right)$ do not hold excess cash in their checking accounts. Households that frequently rebalance $\left(\gamma_{2}\right)$ hold excess cash in their checking accounts less than $1 \%$ of the time. In contrast, the ZLB constraint binds about $15 \%$ of the time, resulting in households occasionally carrying excess cash in their brokerage accounts. Still, the results for the average equity premium and risk-free rate are quite similar to the results for the version of the model in which the ZLB constraint is ignored.

Gust and López-Salido (2009) also show that the response of equity prices, the equity premium, and nominal interest rates after a monetary shock is qualitatively similar in this version of the model to those discussed in Figure 3. In particular, there is still a liquidity effect and a relatively large decrease (increase) in the equity premium following a monetary injection (contraction). Gust and López-Salido (2009) also emphasize the procyclical movements in velocity shown in Table 1, which occurs because demand for liquidity surges in very bad states of the world. In such states, there is heightened risk, and precautionary savings drive down the economy's nominal rate to its lower bound. 
Table 1: Statistics from Model Economies

\begin{tabular}{|l|c|c|c|}
\hline & $\begin{array}{c}\text { Endogenous } \\
\text { Rebalancing }\end{array}$ & $\begin{array}{c}\text { Endogenous } \\
\text { Participation }\end{array}$ & $\begin{array}{c}\text { Representative } \\
\text { Agent }\end{array}$ \\
\hline$E\left(r^{e}-r^{f}\right)$ & 5.4 & 0.5 & 0.4 \\
$E\left(r^{f}\right)$ & 0.7 & 3.7 & 3.7 \\
$\sigma_{\Delta c}$ & 3.4 & 3.8 & 3.5 \\
$\frac{E\left(c_{A}\right)}{E(c)}$ & 1.08 & 1.75 & 1 \\
$\frac{\sigma_{\Delta c A}}{\sigma_{\Delta c}}$ & 3.8 & 1.09 & 1 \\
Percent of Active Types & 20.0 & 28.8 & 100 \\
Average Fixed Cost $(\%$ of GDP) & 0.26 & 8.8 & 0 \\
$\rho(V, Y)$ & 0.23 & 0 & 0 \\
Percent of Time at ZLB & 15.7 & 0 & 0 \\
Percent of Time $a\left(\gamma_{2}, s^{t}\right)>0$ & 0.2 & 0 & 0 \\
Percent of Time $a\left(\gamma_{3}, s^{t}\right)>0$ & 0.0 & 0 & 0 \\
$A\left(\gamma_{2}\right)$ & 0.25 & 0 & 0 \\
$A\left(\gamma_{3}\right)$ & 0.35 & 0 & 0 \\
\hline
\end{tabular}

Note: The equity premium, the real rate, and the standard deviation of consumption are expressed at an annual percentage rate. 